\title{
TA Treatment of Depression - A Hermeneutic Single-Case Efficacy Design Study - 'Linda' - a mixed outcome case
}

\author{
(C) 2013 Mark Widdowson
}

\begin{abstract}
Hermeneutic Single-Case Efficacy Design (HSCED) is a systematic case study research method involving the cross-examination of mixed method data to generate both plausible arguments that the client changed due to therapy and alternative explanations. The present study is the fourth article of a case series which has investigated the process and outcome of transactional analysis psychotherapy using Hermeneutic Single-Case Efficacy Design (Elliott 2002). The client, Linda, was a 45 year old white British woman with mild depression who attended nine sessions of therapy. The conclusion of the judges was that this was a mixed-outcome case: whilst the client improved over the course of therapy and was positive about her experience of therapy, her changes did not last when she experienced considerable stressful events during follow-up. Linda provided a detailed and idiosyncratic description of the aspects of the therapy which were most helpful for her. A cross-case comparison with other cases in this series suggests several interesting features which are worthy of further investigation. Specifically, the use of a shared theoretical framework and an egalitarian therapeutic relationship were helpful. As with other cases in this series, the client experienced positive changes in her interpersonal relationships suggesting that this outcome of TA therapy warrants further investigation
\end{abstract}

\section{Key words}

Depression; Hermeneutic Single-Case Efficacy Design; Case Study Research; Transactional Analysis Psychotherapy.

Editor's Note: For the $1^{\text {st }}$ paper in this series, which appeared in IJTAR 3:1, the author provided detailed appendices: the case record, affirmative and sceptic cases, judges' opinions, and various templates including adherence checklists.

\section{Introduction}

This is the fourth and final Hermeneutic Single-Case Efficacy Design (Elliott, 2002) study in the current case series conducted by the author as part of his doctoral research investigating the process and outcome of TA psychotherapy for depression. This case presents an ambiguous picture of change where an initial examination of the results suggests no clear and immediately obvious conclusion regarding outcome. This is perhaps the sort of situation where HSCED shows particular strength as an investigation method by developing arguments which account for this mixed picture of change and then seeking external verdicts regarding the outcome of the case.

HSCED (Elliott, et al., 2009) is a systematic case study research method which examines individual cases and can be used to:

(a) evaluate whether change has occurred;

(b) examine evidence causally linking client change to the therapy;

(c) evaluate alternative explanations for client change; and

(d) identify the specific processes that appear to have been responsible for change.

Evidence taken from a rich case record is subjected to an intensive analysis and cross-examination. This process concludes with an adjudication procedure whereby judges offer their verdict regarding the outcome of the case; this includes consideration of extra-therapy events as contributing to client change and a number of process variables from within the therapy that may have been beneficial. The evidence that is used in a HSCED study is based on a rich case record of the client and their therapy and uses both quantitative and qualitative data 
which is sifted through, evaluated and triangulated with other data sources to generate plausible arguments regarding the extent and process of change within the individual case.

Three previous HSCED-based case studies have demonstrated the effectiveness of TA psychotherapy for the treatment of depression (Widdowson, 2012a, b, c). Specifically, these cases have shown that TA can be an effective therapy for depression when delivered in routine clinical practice, in private practice settings, with clients who actively sought out TA therapy and with white British therapist and client dyads.

Case study research is rapidly gaining momentum within the TA world, with several researchers contributing to the TA evidence-base using case studies. In addition to the cases of Widdowson (2012a, b, c), case studies have been used to demonstrate the effectiveness of TA for people with long term health conditions (McLeod, 2013) and (in this present journal) with a client with emetophobia (Kerr, 2013). Clearly further research needs to be done to both replicate and confirm these findings and to push the accumulation of evidence of the effectiveness of TA into applications with other client groups.

Such case study research provides a good example of the use of methodological pluralism (Slife \& Gantt, 1999) whereby a range of research methods can be combined to develop a compelling body of evidence. For example, the above studies complement the quantitatively-based study of van Rijn et al. (2011) which also found TA to be an effective therapeutic approach. Furthermore, as case study research accumulates, it becomes easier to make comparisons between cases and to increase specificity and transferability of findings by using cross-case analysis methods (Iwakabe and Gazzola, 2009; Iwakabe, 2011). This article concludes with a brief cross-case analysis which compares the findings from this case to others in this series.

\section{Method}

\section{Participants}

Client

Linda was a 45 year old woman who lived with her husband of over 20 years, with whom she described having a loving and supportive relationship. At the time of entering therapy Linda had been unemployed for over two years after having walked out of her last job where she had experienced bullying from the management team. Since then she had been at college for a year studying digital graphics. When she started therapy she said she had lost confidence in herself and her ability to put herself forward at interviews and to 'fit in'.

Linda had a difficult relationship with her mother and described her as a cold and critical woman and stated that she could not remember her mother praising or being nurturing towards her during her childhood. Due to all of this, and despite her mother having recently being diagnosed with terminal cancer, during the course of therapy Linda stated that she did not love her mother. Linda had a younger sister with whom she enjoyed a close relationship.

Linda had no previous experience of therapy and was apprehensive about the process and slightly ambivalent about attending, concerned that perhaps she was not in a 'bad enough way' to merit therapy time. She was generally in good health and had a close circle of friends by whom she felt supported.

She felt her main problem stemmed from her interaction with others. She described herself as 'too much for others' and in situations in which another person might end up feeling upset she ended up taking responsibility for the interaction and feeling guilty. Over time she generally had lost her confidence and had effectively shut herself off from others and was doing less and less and staying in the house most of the time and avoiding socialising with others. She was also feeling guilty about her emotional distance with her mother and was frustrated with herself and her 'lack of direction in life'.

Linda was an intelligent, thoughtful, articulate woman. She had a good sense of humour and was able to reflect and challenge herself about the views she held about herself, others and her life. She had a curiosity about her process and was robust in her challenge of the therapist if she was unsure or felt something did not fit for her.

Due to her unemployment, Linda could not afford private therapy so self-referred to a local voluntary agency and was allocated a therapist, paying a small donation for sessions. At her initial meeting with her therapist, the therapist ascertained that she did not meet any excluding criteria for participation in the study and conducted a brief clinical diagnostic interview to confirm diagnosis of major depressive disorder based on DSM-IV diagnostic criteria (APA, 1994). She was screened using CORE-OM and BDI-II and met the criteria for 'caseness' and inclusion in the study. Linda's clinical score using CORE-OM was 16 , indicating mild levels of distress and functional impairment and her BDI-II score was 19, indicating mild depression. She was seen in a naturalistic therapy protocol for a period of nine weekly individual sessions. Linda had been offered up to 16 sessions, but felt sufficiently improved after 8 sessions and had found a new job so decided to end therapy and attended for a final ending session.

\section{Therapist and Treatment}

The therapist in this case was 'Michelle', a 42 year old, white British female therapist. At the time of starting therapy with Linda, Michelle had just over 1 year post qualifying experience as a Certified Transactional Analyst (Psychotherapy). Michelle had at least one hour of supervision per month on her work with Linda with an 
experienced Provisional Teaching and Supervising Transactional Analyst (Psychotherapy).

The therapy primarily focused on identifying and challenging how Linda experienced and interpreted the world, interactions with others and the conclusions she drew about herself. The exception to this focus was in session four which mainly focused on exploring her relationship with her mother.

From a TA perspective, the therapy consisted of an initial phase (sessions one to three) of the therapy focused on problem formulation and the use of the ego state model and racket system to facilitate identifying maladaptive cognitive and behavioural patterns and ways of interpreting the world and others. This initial phase also included identifying self-critical dialogue and encouragement to move towards her goals. The second phase (sessions four to seven) of the therapy involved exploring interpersonal patterns (transactions, games) and developing communication strategies, exploring her relationship with her mother which involved deconfusion by encouraging the expression of previously disavowed and repressed anger, challenging maladaptive beliefs about self and others (rackets, contaminations, discounting) and ways of interpreting the world and her self-critical internal dialogue. This phase concluded at session seven when the therapy moved to identifying specific contract goals and behavioural contracting for change. The ending phase of the therapy (sessions eight and nine) involved accounting for and celebrating Linda's changes.

In her Change Interview and HAT forms, Linda described the therapy as being a focused and boundaried relationship which emphasised drawing out her assumptions and meaning-making processes and maladaptive beliefs about self, others and the world and the impact of these on her interpersonal relationships. She also described how the therapy sought to identify, explore and re-evaluate these thinking processes and interpersonal patterns and involved Linda 'being held to account' and both expected to implement changes and given active encouragement to support these changes.

Analysis Team

(This paragraph is reproduced from Widdowson 2012b, $c$, as the analysis team members and process of analysis was identical)

The analysis team who generated the affirmative and sceptic arguments was comprised of 7 students in training for the Certified Transactional Analyst (Psychotherapy) qualification, who attended a full-day case study research analysis workshop. All postfoundation year trainees at the training institute involved were sent an e-mail invitation to attend and participants in the analysis self-selected. The workshop was intended to provide experiential learning of case study research analysis and was co-facilitated by the author and Katie
Banks, Certified Transactional Analyst (Psychotherapy). (Ms Banks had participated in the analysis of the case of 'Peter'). Participants had been sent copies of the rich case records, plus an article describing the HSCED method one week prior to the workshop. The workshop commenced with a one-hour presentation on the HSCED method, following which the students read the rich case record and were split into two groups; one group formed the affirmative case, and the second group formed the sceptic case. Each group was facilitated by one of the co-facilitators who assisted the group members in developing their arguments.

\section{Judges}

The judges in this case were; Dr Meghan Craig, a phenomenological-existential oriented counselling psychologist based in London; Katrin Heinrich, a personcentred/emotion-focused counsellor from Germany who is currently conducting a HSCED study for her MSc in Counselling with the University of Strathclyde and Catherine Cowie, a person-centred therapist based in Scotland. Prior to working as a therapist, Catherine was a lecturer in physics, mathematics and statistics. She has a particular interest in client change processes in therapy.

\section{Measures}

(The section below has been reproduced from Widdowson, 2012a as all measures and the procedure for administration of these was identical to the previously reported case of 'Peter')

\section{Quantitative Outcome Measures}

Two standardised self-report outcome measures were selected to measure target symptoms (Beck Depression Inventory - BDI-II) (Beck et al. 1996) and global distress/ functional impairment - CORE-OM (Barkham et al., 2006). These were administered before the first session, and at sessions 8 (mid-way through therapy) and 16 (end of therapy). These measures were also administered at the one-month, three-month and six-month follow up periods. These measures were evaluated according to clinical significance (client moved into a non-clinical range score) and Reliable Change Index (Jacobson and Truax, 1991) (non-clinically significant change). See Table 1 for Reliable Change Index $(\mathrm{RCl})$ values for each measure.

\section{Weekly Outcome Measures}

In order to measure on-going progress, and to facilitate the identification of key therapeutic events which produce significant change, two weekly outcome measures were administered prior to the start of each session. These were CORE-10 (Connell et al 2007), a ten item shortened version of the CORE-OM which has good correlation with CORE-OM scores and can be used to monitor change. The second measure was the simplified Personal Questionnaire (PQ) (Elliott, et al, 1999). This is a clientgenerated measure in which clients specify the problems they are wanting to address in their therapy, and rate 
their problems according to how distressing they are finding each problem. The PQ was also administered at each of the three follow-up intervals.

\section{Qualitative Outcome Measurement}

Qualitative outcome data was collected one month after the conclusion of the therapy. The client was interviewed using the Change Interview protocol (Elliott et al, 2002) a semi-structured qualitative change measure which invites the client to explain how they feel they have changed since starting therapy, how they think these changes came about, what they felt was helpful or hindering in the therapy, and what changes they feel they still need to make. As part of this, the client identifies key changes they have made and indicates using a five-point scale whether they expected these changes, how likely these changes would have been without therapy, and how important they feel these changes to be.

\section{Qualitative Data about Helpful Aspects of Therapy}

In order to gain data regarding specific events or aspects of the therapy the client found useful, the client completed the Helpful Aspects of Therapy (HAT) (Llewelyn, 1988) at the end of each session. The HAT asks the client to describe both the most and least helpful aspects of the therapy session and to rate the helpfulness/ unhelpfulness of the session.

\section{Therapist Notes}

The therapist also completed a structured session notes form at the end of each session. The therapist provided a brief description of the session and key issues, therapy process, the theories and interventions they used and indicated how helpful they felt the session was for the client.

\section{Adherence}

The therapist also completed a twelve-item adherence form at the end of each session, rating the session on a sixpoint scale. The therapist's supervisor also rated the therapist's work using the same form to verify therapist competence and adherence in providing identifiably TA therapy. (Widdowson, 2012a: 53-55)

\section{HSCED Analysis Procedure}

(Note: this section has also been reproduced from Widdowson, 2012a as the guidelines for the development of both the affirmative and sceptic cases are identical to those for the previous case)

\section{Affirmative Case}

The affirmative case is built by identifying positive and convincing evidence to support a claim that the client changed and that these changes primarily came about as a result of therapy. In line with HSCED procedure, to make a convincing case that the client changed positively and as a result of therapy, the affirmative case must be built by identifying evidence for at least two of the following:

1. changes in stable problems: client experiences changes in long-standing problems

2. retrospective attribution: client attributes therapy as being the primary cause of their changes

3. outcome to process mapping: 'Content of the posttherapy qualitative or quantitative changes plausibly matches specific events, aspects, or processes within therapy' (Elliott et. al, 2009; 548)

4. event-shift sequences: links between 'client reliable gains' in the $P Q$ scores and 'significant within therapy' events

\section{Sceptic Case}

The sceptic case is the development of a good-faith argument to cast doubt on the affirmative case that the client changed and that these changes are attributable to therapy. It does this by identifying flaws in the argument and presenting alternative explanations that could account for all or most of the change reported. Evidence is collected to support eight possible non-therapy explanations. These are:

1. Apparent changes are negative or irrelevant

2. Apparent changes are due to measurement or other statistical error

3. Apparent changes are due to relational factors (the client feeling appreciative of, or expressing their liking of the therapist or an attempt to please the therapist or researcher) (note, this is a term used in the HSCED approach and does not refer to the impact of the therapeutic relationship as a vehicle for change and relates to factors not directly within the therapy process. The reader is invited to notice the different ways that 'relational' is used within this report, which include this criteria, the therapeutic relationship and a relational approach to therapy)

4. Apparent changes are due to the client conforming to cultural or personal expectancies of change in therapy

5. Improvement is due to resolution of a temporary state of distress or natural recovery

6. Improvement is due to extra-therapy factors (such as change in job or personal relationships etc)

7. Improvement is due to biological factors (such as medication or herbal remedies)

8. Improvement is due to effects of being in the research

Once the sceptic case had been presented, the affirmative team developed rebuttals to the sceptic case. The sceptic team then developed further rebuttals to the affirmative rebuttals, thus providing a detailed and balanced argument. 


\section{Adjudication Procedure}

The rich case record and the affirmative and sceptic cases and rebuttals were then sent to the independent judges for adjudication. The judges were asked to examine the evidence and provide their verdict as to whether the case was a clearly good outcome case, a mixed outcome case, or a poor outcome case; to what extent the client had changed and to what extent these changes had been a result of therapy; and to indicate which aspects of the affirmative and sceptic arguments had informed their position. The judges were also asked to comment on what factors in the therapy they considered to have been helpful and which characteristics about the client did they think had contributed to the changes. (Widdowson, 2012a: 6)

\section{Results}

Quantitative Outcome Data

Linda's quantitative outcome data is presented in Table 1 and Figures 1 and 2. Linda's initial scores were just above the 'caseness' cut-off range for inclusion in this study. Her BDI-II score at entry into therapy was 19 , indicating mild depression and her CORE-OM score was 16 , indicating mild levels of global distress and functional impairment. Linda's CORE-OM and BDI-II scores had demonstrated clinically significant change by session eight, with all measures showing clinically significant change by session nine. This improvement was maintained at the first follow-up period, but then Linda showed marked deterioration at the three-month followup, with her BDI-II score showing reliable improvement to just above clinical levels of distress at the six-month follow-up.

\section{Qualitative Process Data}

Linda's changes as identified in post-therapy Change Interview are shown in Table 2.

\section{Client Feedback from Three Month Follow-Up}

At the three month follow up, Linda completed the CORE-OM, BDI-II and PQ. She attached a note to the forms, letting the researcher know that things had been difficult over the previous few weeks. The company she had worked for had gone bust a month earlier, and she had been made redundant. She also informed the researcher that her mother had died two weeks prior to the follow-up, following a long deterioration during which Linda had taken on some carer responsibilities. She also stated 'I realised when I filled in the form you might be concerned. Don't worry - last week was bad, but this week is a bit better. As you know, I have a lot of support - so when I'm down, there are people who can help. Despite having a setback, I still think the (therapy) helped. I'm better able to articulate my feelings and not bottle it all up.'

Client Feedback from Six Month Follow-Up

At the six month follow-up, in addition to completing the CORE-OM, PQ and BDI-II Linda enclosed a note stating that; 'I am OK in general, but still unemployed and worried for the future. I am not clear what I should do to increase my chances of employment, however I am keeping myself well physically through regular exercise, less drinking and taking care of myself emotionally. My mum died a few months ago and it's been fine dealing with her death. I don't feel we had unfinished business and I feel able to cope - I was sad, and still am, but am not wrecked by her death. Although it can appear as though I'm back to feeling as I was pre-therapy, I don't think I am. I am a bit up and down, but therapy has helped me be calmer and have a clear eyed look at my life. It's never going to be easy, but I don't feel utterly overwhelmed'.

Analysis of Change Interview responses

For Linda, the professional relationship aspect of the therapy was important.

CL2: ... I really liked the professional relationship. I liked that I was paying. I liked that this was an hour a week that I could take all that stuff and so it clarified things. So if you had things going on during the week you could just park that up and say I can take that... She wasn't your friend who was going to say you are great and you're fine. You could be challenged, you know.

CL15: (in therapy), you have to go a bit deeper... Somebody maybe just asking you more pertinent questions, asking you to kind of look at what you're saying in a bit more depth

She found the therapist's challenge and depth of questioning helped her to maintain focus on the problem areas and also in identifying and changing her maladaptive patterns

CL17-20: So, it's kind of people picking things up that they might not have otherwise. But I suppose it could be just asking, "What do you mean by that?" or "why is this an issue?", or whatever. So, it is just going a bit deeper. I don't think it was... (short pause), again it's not magic. It's just talking but it is talking in a particular way... Which is more structured... I guess I it makes you consider things a bit more. It just makes you think through a bit more. I suppose in between sessions you are more aware of things that you have discussed and trying to kind of looking at that and think oh yeah, we talked about this and now in the situation and how l'm dealing with it and because it is more structured so there is somebody bringing you back to the main points.

This combination of a safe, professional relationship and sustained focus on her inner process assisted her in challenging and disconfirming her maladaptive internal and interpersonal patterns.

CL46: ... well for me it's a lot about that relationship, right, so there has to be notions of trust and so you are in a 


\begin{tabular}{|c|c|c|c|}
\hline & Beck Depression Inventory-II & CORE-OM & $\begin{array}{c}\text { Personal Questionnaire } \\
\text { (mean score) }\end{array}$ \\
\hline Clinical cut-off & 10 & 10 & 3.00 \\
\hline Caseness cut-off & 16 & 15 & 3.50 \\
\hline Reliable Change Index & 5.78 & 46.0 & 1.00 \\
\hline Pre-Therapy & 19 & 16 & 5 \\
\hline Session 8 & $2(++)$ & $2(++)$ & $3.1(+)$ \\
\hline Session 9 & $0(++)$ & $2(++)$ & $2.4(++)$ \\
\hline 1 month Follow-up & $0(++)$ & $4(++)$ & $2.1(++)$ \\
\hline 3 month Follow-up & $23(-)$ & $11(+)$ & 4.7 \\
\hline 6 month Follow-up & $12(+)$ & $11(+)$ & 5 \\
\hline
\end{tabular}

Note: Values in bold are within clinical range. + indicates Reliable Change, ++ indicates clinically significant change.

Figure 1: Weekly and Follow-Up CORE-10 scores (clinical significance 10)

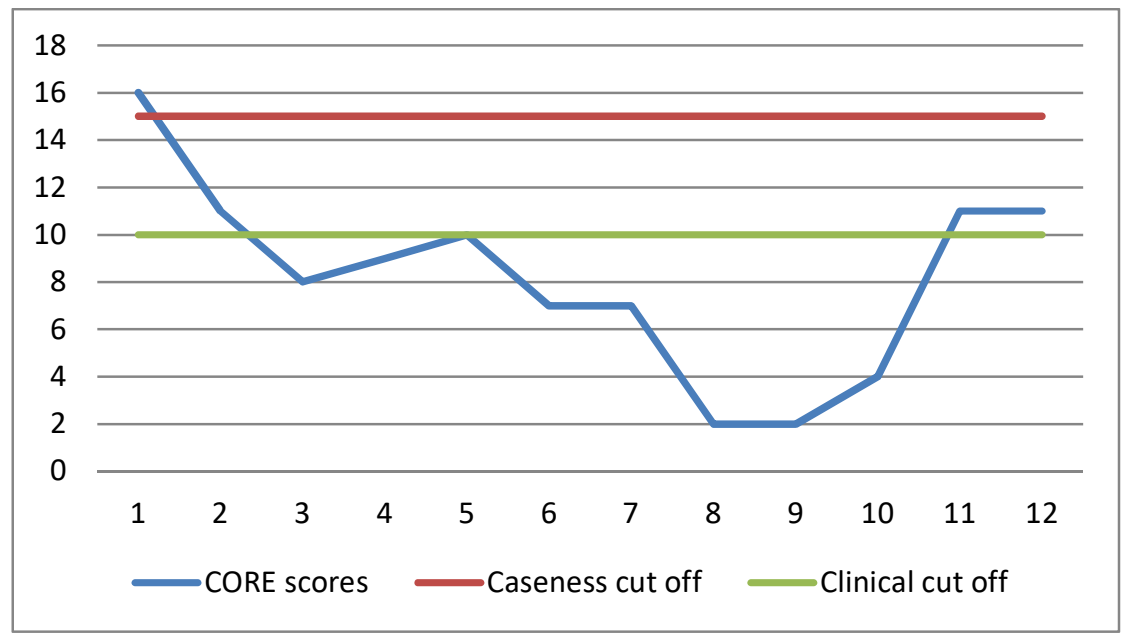

Figure 2: Weekly and Follow-Up mean PQ scores (clinical significance 3)

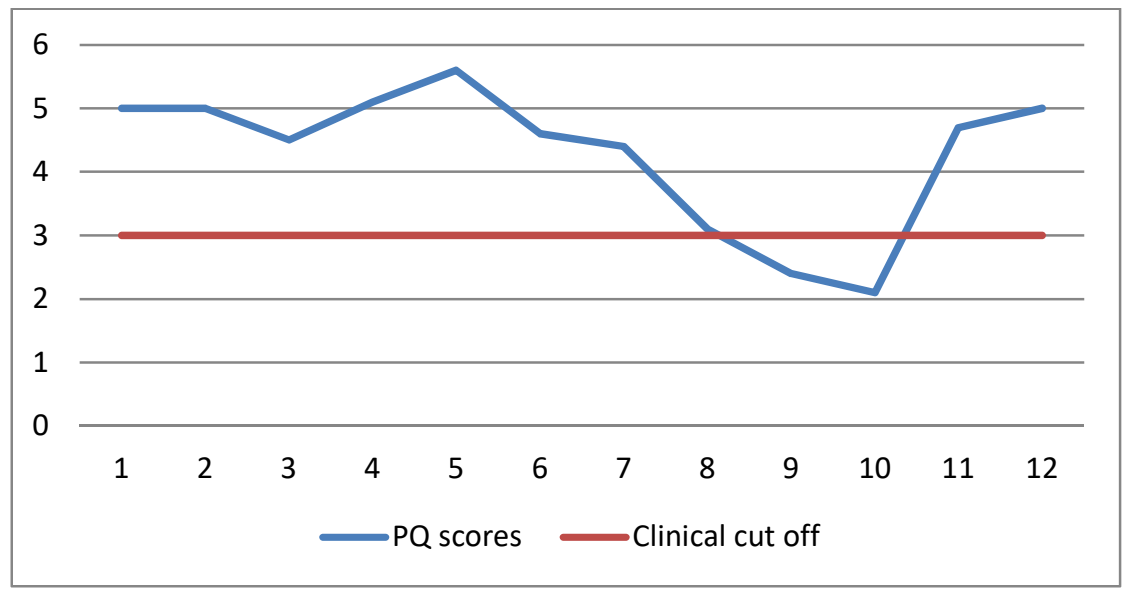

Note: 10,11 and 12

relate to the follow-up periods 
Table 2: Linda's changes as identified in post-therapy Change Interview

\begin{tabular}{|c|c|c|c|}
\hline 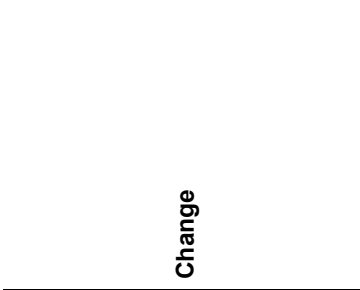 & 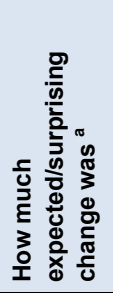 & 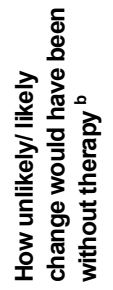 & 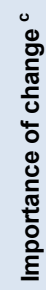 \\
\hline Feeling calm and competent & 2 & 2 & 5 \\
\hline $\begin{array}{l}\text { Not making assumptions and } \\
\text { changing how I relate to people }\end{array}$ & 4 & 1 & 4 \\
\hline $\begin{array}{l}\text { Being more open, vulnerable } \\
\text { and less tense }\end{array}$ & 2 & 1 & 3 \\
\hline $\begin{array}{l}\text { Feeling OK about my } \\
\text { relationship with my mum and } \\
\text { not feeling guilty }\end{array}$ & 4 & 1 & 5 \\
\hline
\end{tabular}

a,b The rating is on a scale from 1 to 5 ;

$1=$ expected, $3=$ neither, $5=$ surprising

${ }^{c}$ The rating is on a scale from 1 to 5 ;

$1=$ slightly, 3 = moderately, $4=$ =very, $5=$ =xtremely

room with somebody who trusts you, you trust and you can talk about what you identify as being important to you. You are in the driving seat. What's bugging you, what's irritating you? You put it out there and there's a discussion about it. This is an equal relationship. There is not anyone telling you what to feel about it, what to think about it, what to do about it. It's putting stuff out there and kind of looking at it from different angles. I suppose it's like you put something down and you can walk around and you can look at it. You can examine it. It kind of takes it out of your head

CL52-4: There is that process of kind of making yourself vulnerable, it has to go out there and again I suppose in the therapy situation you have got a safe space to do that. It's good to test things out if you like. Within there, all of things you have going round in your head thinking "I am bonkers". This is just bonkers, why am I thinking that? If you put it out there, oh look! You know, the world is still turning. Nothing has happened, no bad things have happened, you can talk about this. The world is here and everything is fine and this is ok.

CL60: It is a qualitative difference from just sitting down with your mates, your partner, whatever ... So it's not just about the talking. Constructive dialogue... Where you have very, very strong focus on a particular thing and you are seeking to kind of deconstruct it, put it back together, do whatever with it to try and make sense of it

\section{Additional comments}

Linda was emphatic that participating in the research had not been problematic for her. She was also clear that there had not been any aspects of her therapy which had felt incomplete and she did not identify any aspects of therapy which had been unhelpful. Although she stated that she had found the ego state model helpful, she did express a natural aversion to anything which might be 'putting people into boxes'.

\section{HSCED Analysis}

Affirmative Case

Linda identified nine main problems which she was seeking to resolve in psychotherapy, all of which had reliably changed by session eight and had changed at the level of clinical significance by the final ninth session. These changes were sustained at one-month follow-up. Although Linda demonstrated deterioration on outcome measures at both the three and six-month follow-up periods, the affirmative team's perspective was that this could be accounted for by her mother's death and her long period of unemployment. Linda was quite emphatic in her statements at the three and six-month follow-up that she felt different and that the therapy had helped and that she was coping with things differently to her pretherapy state.

In considering the quantitative measures, the affirmative team highlighted that by session eight Linda's BDI-II scores had dropped 17 points to 2 and her CORE scores had dropped 14 points to 2 - both within the 'normal range' which was maintained at one month follow-up. Her $\mathrm{PQ}$ scores also demonstrated clinically significant change by the end of therapy and at one month followup. Although there was some deterioration in Linda's $P Q$ scores at six-month follow-up compared to end of therapy, five of her nine scores still demonstrated reliable change from pre-therapy scores, again suggesting that some permanent changes had taken place, and that the deterioration was possibly a reactive effect of prolonged and extreme stress.

The affirmative team noted Linda's clarity and specificity in the changes she had experienced in her Change Interview, and in Linda's conviction in her three and six month follow-up statements that she was coping with things better than she had done prior to therapy. Associated with this, the affirmative team highlighted that Linda has identified five contract goals for her therapy which she felt she had achieved and which her three and six month statements suggest were maintained. These were:

- To work out what I want to do in my life

- To feel OK about my relationship with my mother

- To check out assumptions I make

- To share my vulnerability with family and friends

- To challenge the beliefs I hold about myself 
The affirmative team noted that throughout her Change Interview, Linda clearly attributed her changes to therapy and provided a clear and detailed description of therapy process which they argued provided a convincing account of change. Indeed, in both her HAT forms and her Change Interview, Linda provided considerable detail about the helpful aspects of the therapy process which the affirmative team considered provided clear and plausible links between therapy process and outcomes.

The affirmative team also noted that although the biggest changes for Linda took place after her job offer, her CORE scores had showed clinically significant change within the first three sessions, prior to her job interview, and that this provided evidence that therapy had been a causal factor in Linda's changes.

\section{Sceptic Case}

The sceptic team concluded that there was strong evidence to cast doubt on claims that Linda changed substantially and that these changes were due to therapy, highlighting three major lines of evidence. Firstly, Linda demonstrated the largest change after securing a new job, suggesting external factors were highly significant in causing her apparent changes. Secondly, Linda's changes were not maintained during the follow-up, suggesting that her changes were temporary - indeed during the follow-up period Linda experienced a bereavement and redundancy and these clearly had a significant impact on her, leading to reliable deterioration which casts doubt on any claims of internal changes having taken place during therapy. Thirdly, the sceptic team felt that there was reason to consider that relational factors and Linda's liking of her therapist may have accounted for some of her reported enthusiasm and positivity about therapy.

\section{Affirmative Rebutta}

Linda was clear in her three and six month follow-up statements that although there was apparent deterioration, she did not feel that she was in the same situation as she was prior to therapy. Furthermore, she felt that she had made some permanent changes in how she related to others, and how she resourced herself. She was also clear that her deterioration was due to the effect of external factors - in particular her mother's death and her redundancy.

Linda described herself as analytical and cynical, and had been sceptical about therapy at the outset. In light of this, the affirmative team considered it unlikely that someone with this degree of scepticism would be painting an overly positive picture of therapy if they did not genuinely believe it to be true. She was clear that her therapist was active and often challenging, but that this was an aspect of the therapy that she welcomed. She also suggested that her therapist did not adopt an 'overly nice' position in relation to her and had clear expectations of Linda and that she had found this robust and challenging approach to be a catalyst for change which suited her own personality. Although Linda was positive about her therapy, the affirmative team felt that her detailed and idiosyncratic account of the therapy process provided sufficient evidence that Linda's change was not due to relational factors.

\section{Sceptic Rebuttal}

The sceptic team maintained that Linda's deterioration in all her outcome measures cast substantial doubt over claims that Linda changed very much during therapy and that any changes were transient and not stable under stress. Despite her statements during follow-up that she was handling problems differently, the sceptic team noted that several of her initial problems had returned to clinical levels. The sceptic team believed that there was a strong argument to believe that Linda's positive changes were more likely to be associated with extratherapy factors, in particular getting a new job, rather than indicative of personal changes due to therapy.

\section{Adjudication}

All judges independently produced their opinions and ratings of the case which are presented in Table 3. A mean score has been given to represent a balance of their conclusions.

To summarise, the judges concluded that Linda had indeed changed during therapy, and that therapy had been important in facilitating these changes, but that these changes were not lasting and were not sustained in response to stressors.

Summary of opinions regarding how the judges would categorise this case

(Clearly good outcome - problem completely solved, Mixed outcome - problem not completely solved, Negative/ Poor Outcome)

The judges agreed that there was evidence that Linda had changed during therapy; however they noted her deterioration during the follow-up period as suggestive that her changes had not been sustained and therefore concluded that this was a mixed outcome case.

Judge A commented 'the client clearly attributes her changes to therapy and provides idiosyncratic detail about how these changes have been maintained at follow-up even though the outcome scores would suggest otherwise. It would appear that the therapy process has given the client resources for coping despite distressing life events occurring post-therapy, and her qualitative accounts seem to confirm that she has found the process useful in helping her cope with these challenges.' Judge $C$ made similar comments, and was particularly struck by Linda's assertion that she was relating to people differently at the end of therapy.

The judges agreed that the impact of external factors had both positive and negative effects on the outcome of the 
therapy, with Linda improving considerably during the course of therapy after succeeding in finding a job after her long unemployment (she attributed her success in interview to therapy) and then her post-therapy decline which she attributed to the effects of bereavement and redundancy from her new job.

One judge considered the possibility that Linda was still in a period of adjustment following these events and that a longer follow-up period would have provided information on whether she would return to an improved level of functioning. Judge $C$ noted that simultaneous improvement on CORE and BDI showed a convincing sign that real change had indeed taken place and agreed that adverse life-events post therapy were most likely the reason for her seeming deterioration, as opposed to any reversal of changes.

Judge B noted that in her statements during the followup, 'Linda described feeling differently and able to cope with situations better. It seems as if she changed her personal strategy to change (Mackrill, 2008) from having to cope with things on her own and drinking alcohol to being willing to show her vulnerability and trust people to being accepting of her perceived weaknesses. This change allowed her to stay connected with others and being open to different perspectives or help. Also it appears that therapy helped her to cope with unfinished businesses related to her mother; she described throughout that the sense of guilt had been worked through. Also when being asked what helped her to get the job, she referred to her increased self-confidence which she attributed to therapy.

Summary of opinions regarding the extent to which the client had changed

The majority verdict of the judges was that Linda had changed substantially during therapy - achieving reliable, clinical change, but these changes had not been sustained during the follow-up.

Judges $A$ and $C$ noted that the affirmative team's argument that Linda's distress at the 3 month follow-up was due to the effects of acute grief and recent redundancy was plausible and was supported by improvement to sub-clinical range on BDI-II at six month follow-up.

Judge A noted that 'there is a contradiction between the client's outcome scores, and the self-report statements about how she is coping, and doing better than the outcome measures would indicate. The question here is whether the outcome measures were accurately examining the areas of change reported, or whether the client was attempting to reconcile some dissonance she felt about the process by affirming that she had indeed changed permanently despite the lack of evidence in the outcome scores.'
Summary of opinions as to whether the changes were due to the therapy

The judges agreed that Linda had provided a detailed, consistent and idiosyncratic account of the key aspects of the change process but disagreed about the affirmative team's arguments regarding processoutcome matching and event-shift sequences, with judges $A$ and $C$ considering these to be plausible and judge $B$ being unconvinced by them. Judge $A$ in particular felt impacted by Linda's emphatic statements of the helpfulness of therapy in her change interview, stating 'The qualitative data from the Change Interview is important in this decision about whether the client changed during therapy. The client reports clearly indicate that she feel she changed substantially with four significant changes identified. These changes correspond to the client's therapeutic goals, and were identified as important/very important by the client. I think this is corroborated by the evidence in particular HAT descriptions which correspond to these changes. Since particular therapy events were highlighted by the client as being helpful, and because these correspond with the identified changes at the follow-up interview, there is a more substantive argument that the process of therapy was helpful in bringing about client change'. Judge C made very similar observations.

Judge B commented on the impact of external factors on the changes Linda experienced, in particular her new job which she felt 'prompted a substantial shift in outcomes and led to a rapid conclusion of therapy. Nevertheless, it appears that therapy facilitated this process by helping the client to gain more confidence in preparation for the job interview. I would question the stability of these changes, however, because outcomes during follow-up were negatively affected by external factors such as loss of job and death of mother. Undoubtedly, these factors would have had a significant impact on the client, but the qualitative reports from the client indicate that the changes during the course of therapy helped her to cope with these difficulties better, even some time after therapy ended. It appears that therapy factors and external life factors are closely inter-linked in these outcome areas. For this reason, I would say that the changes the client reported at the end of therapy were largely the result of the therapy experience, but that external factors also played a role in moderating these effects.'

Judges B and C also went on to note Linda's clear retrospective attribution of therapy as a catalyst for change and being important to take into account and felt that this, combined with the role Linda attributed to therapy in enabling her to work through her guilt and unfinished business in her relationship with her mother, were all clear evidence that therapy positively contributed to her changes. 


\section{Mediator factors}

Judge A highlighted 'the... non-judgemental nature of the therapist (as being)... a very important factor in building a strong therapeutic alliance. This seems to have paved the way for the work done in therapy, as the client seemed able to trust her therapist, and to be challenged by her. The therapist's manner of questioning and challenging the client was an apparent mediator in the change process.

Judge B highlighted the role of feedback given to the client by her therapist as likely to have been an important mediator factor. In particular she highlighted Linda's' remarks in the HAT descriptions that the feedback on her behaviours and way of being was helpful to her in beginning to think about a different way of being and relating to others.' Judge $B$ also noted the sense of trust and equality in a relationship with a fully engaged therapist and the structure and boundaries of the therapy as being likely mediator factors. Furthermore, judge $B$ highlighted some key intervention approaches which Linda found helpful, which included the therapist's sustained focus, in-depth questioning, exploration of issues and offering alternative perspectives. Judge $B$ considered that these may have caused change by helping Linda to increase her awareness, change her frame of reference, develop a new narrative, encouraged and reinforced her change process. Judge $B$ also commented that the main therapeutic strategy which appeared to be relevant in guiding this process was the therapist's focus on helping Linda to identify, re-evaluate and change problematic thinking and behaviour patterns.

Judge $C$ highlighted the helpfulness of the use of theory to help Linda conceptualise her process, combined with a sense of equality in the relationship and of 'being met' by her therapist as significant.

All judges agreed that the therapist's affirmative, validating and permissive approach enabled Linda to experience a sense of acceptance and gave her hope that things might change. This was balanced with a sense of the therapist being strong, having a sense of humour and maintaining a stance that both encouraged Linda to take charge and make active changes and discouraged avoidance.

\section{Moderator factors}

The judges were also asked to provide an opinion on which client characteristics or resources had been helpful to them in the process of change. The judges agreed that Linda appeared to have a strong social network which was supportive of her changes (in particular her newfound willingness to be emotionally vulnerable in relationships) and provided emotional resources to help her deal with difficult life events. Another helpful factor was considered to have been the fact that Linda had identified problematic coping strategies and issues to work on in therapy prior to attending.

Table 3: Adjudication decisions

\begin{tabular}{|c|c|c|c|c|}
\hline & Judge A & Judge B & Judge C & Median/Mean \\
\hline \multicolumn{5}{|l|}{ 1. How would you categorise this case? How certain are you? } \\
\hline 1a. Clearly good outcome (problem completely solved) & $60 \%$ & $\begin{array}{c}\text { (no score } \\
\text { given) }\end{array}$ & $0 \%$ & $\begin{array}{c}\text { (mean } \\
\text { cannot be } \\
\text { calculated) }\end{array}$ \\
\hline 1b. Mixed Outcome (problem not completely solved) & $100 \%$ & $80 \%$ & $80 \%$ & $86 \%$ \\
\hline 1c. Negative/Poor Outcome & $20 \%$ & $\begin{array}{c}\text { (no score } \\
\text { given) }\end{array}$ & $0 \%$ & $\begin{array}{c}\text { (mean } \\
\text { cannot be } \\
\text { calculated) }\end{array}$ \\
\hline 2. To what extent did the client change over the course of therapy? & $60 \%$ & $80 \%$ & $60 \%$ & $66 \%$ \\
\hline 2a. How certain are you? & $80 \%$ & $80 \%$ & $80 \%$ & $80 \%$ \\
\hline 3. To what extent is this change due to therapy? & $60 \%$ & $\begin{array}{c}\text { (no score } \\
\text { given) }\end{array}$ & $80 \%$ & $70 \%$ \\
\hline 3a. How certain are you? & $100 \%$ & $\begin{array}{c}\text { (no score } \\
\text { given) }\end{array}$ & $80 \%$ & $90 \%$ \\
\hline
\end{tabular}


In addition, Linda's motivation, determination and active approach to change was highlighted as an adaptive change strategy, as was her desire to take charge of her life and be 'in the driving seat' of her own therapy. Judges $B$ and $C$ noted that Linda took a series of active steps to breaking her vicious cycle of low self-confidence by pushing herself to go out into the world, her willingness to see things from different perspectives, and her engagement with the contradiction of striving for privacy whilst needing to open up, share problems and be vulnerable in her close relationships. Judge $B$ felt that this enabled Linda to challenge her characteristic way of being in relationships and enabled Linda to have corrective interpersonal experiences which supported her change.

\section{Discussion}

Unfortunately, this case does not add further support to the findings from the cases of Peter, Denise and Tom (see, Widdowson, 2012a, b, and c) with regards the effectiveness of TA psychotherapy for depression. However, this is not a completely poor outcome case, and there are many features of this case which raise some interesting questions about how we can maximise the effectiveness of therapy. It is clear that Linda did indeed change during therapy and found therapy to be a useful experience. It is also clear that the therapy was not sufficient to resource Linda for the difficult times she would face in the months after finishing therapy. As soon as Linda obtained her job around session 8, she was keen to finish therapy. This was earlier than the therapist had expected, and consequently did not give the therapist sufficient time to help Linda with contingency planning and ensuring that she had adequate resources for the future.

A cross-case analysis of the cases in this series has been conducted which has broadly followed the grounded theory method of constant comparison. This has suggested a number of variables and factors which may have influenced the outcome of the therapy and which suggest avenues for further investigation.

Unlike the previous cases (Widdowson, 2012a, b, c), Linda had no knowledge of TA or of therapy prior to starting therapy. It is possible that pre-therapy preparation may be beneficial to outcome. As with the previous cases in this series, Linda's therapist presented relevant TA theory to conceptualise and discuss Linda's problems with her and Linda reported that this had been helpful to her. These findings suggest that the psychoeducational components of TA therapy are beneficial. Associated with the use of theory to generate insight, the therapy involved considerable attention to changing both Linda's internal way of interpreting and responding to the world; i.e. to changing her script and her transactional patterns, and Linda found this to be helpful.
In contrast to the previous three cases, Linda was somewhat sceptical and ambivalent about starting therapy, which may have limited her engagement in the process. Another contrast to the previous cases was the fact that the clients in those cases all actively and specifically sought out a TA therapist, whereas Linda saw the therapist which was allocated to her by the agency. One potential implication for this is that it may be possible that client preferences have an influence on overall outcome of the case. However, Linda found the therapy to be helpful and enjoyed a positive relationship with a therapist she perceived as strong and potent; as in the previous three cases, she also reported experiencing the therapy as being a place where she felt like an equal and as an egalitarian process.

Another similarity with previous cases in this series was that Linda also described an early environment where she felt criticised and undermined. This would suggest that the experience of a non-nurturing and critical environment results in a vulnerability to depression.

Linda, and the clients in the previous cases, experienced improvement in her interpersonal relationships during the therapy. Unfortunately, none of the outcome measures used in this study addressed interpersonal functioning so it is impossible to quantify the magnitude and significance of this change. Further research which examines positive change in interpersonal relationships is clearly warranted.

Linda experienced some considerable life difficulties following therapy, which precipitated considerable distress. Unfortunately, Linda ended therapy early and abruptly, which gave the therapist little opportunity to engage in contingency planning or relapse prevention work. Although insufficient data is available to draw conclusions on this matter, it is possible that attention to relapse prevention and resourcing clients may be beneficial and assist in the maintenance of changes. When contrasted with the cases of Peter, Denise and Tom, Linda's therapy is considerably shorter and it would appear to be plausible to consider that this was a factor.

\section{Limitations}

As with previous cases in this series, the researcher was involved in the analysis teams and had been a former tutor for the group members, which may have influenced their arguments. Also, the analysis team had a relatively short amount of time to construct their arguments, and it is possible that a more detailed picture would have emerged if they had been given more time. Although the conclusions of the judges was that this was a mixed outcome case, the judges were all therapists, and so it is possible that this may have influenced their findings. The use of a lay person acting as a judge in future investigations may be interesting and reveal alternative ways of looking at cases. 
Linda was clear in her statements and qualitative data that she had made interpersonal changes. This matches the findings from the previous three cases in this series. Unfortunately, no measures of interpersonal change were used, and so consequently it is difficult to determine the extent or nature of interpersonal change with these clients. Future research which includes such a measure is warranted.

\section{Conclusion}

The findings of this case suggest that although the client did in fact change as a result of therapy, these changes were not sustained. As a result, this case does not add to the literature on the effectiveness of TA. However, this case does highlight a number of factors which may be relevant to outcome. Linda also provided some interesting and insightful comments about the process and nature of therapy. Overall, the case raises some interesting questions about the nature of therapeutic change. It also raises interesting questions about how evidence from cases is evaluated and in particular, which sources of evidence are more influential in forming conclusions.

Clearly, more research needs to be done to investigate the process and outcome of TA psychotherapy. Specifically, further research which explores the effectiveness of TA for depression is needed to strengthen our existing evidence base.

Mark Widdowson, Teaching and Supervising Transactional Analyst (Psychotherapy), Associate Director, The Berne Institute, PhD student, University of Leicester, can be contacted on: mark.widdowson1@btopenworld.com

The author wishes to thank the members of the analysis team: Jane Bernard, Isabel Burns, Phil Crawley, Mike Day, David Harford, Colin Kerr and Owen Vaughan. Particular thanks also are due to Katie Banks for her invaluable contribution.

The author also acknowledges with grateful thanks the support of Physis Training in Edinburgh, which provided the venue and participants for the workshop at which the affirmative and sceptic cases were developed.

\section{References}

APA (1994) Diagnostic and statistical manual of mental disorder 4th edition (DSM-IV). Washington DC: American Psychiatric Association

Barkham, M., Mellor-Clark, J., Connell, J., and Cahill, J. (2006). A core approach to practice-based evidence: A brief history of the origins and applications of the CORE-OM and CORE System. Counselling and Psychotherapy Research, 6 (1):3-15.

Beck, A. T., Steer, R. A., and Brown, G. K. (1996). Manual for the Beck Depression Inventory-II. San Antonio, TX: Psychological Corporation.
Connell J, Barkham M, Stiles WB, Twigg E, Singleton N, Evans O, Miles JNV (2007). Distribution of CORE-OM scores in a general population, clinical cut-off points, and comparison with the CIS-R. British Journal of Psychiatry 190:69-74.

Elliott, R. (2002). Hermeneutic single case efficacy design. Psychotherapy Research, 12: 1-20.

Elliott, R., Mack, C., \& Shapiro, D. (1999). Client Change Interview Protocol: http://experiential-

researchers.org/instruments/elliott/changei.html accessed 1 July 2012

Elliott, R., Partyka, R., Alperin, R., Dobrenski, R., Wagner, J., Messer, S.B., Watson, J.C. and Castonguay, L.G. (2009). An adjudicated hermeneutic single-case efficacy design study of experiential therapy for panic/phobia. Psychotherapy Research, 19(4-5): 543-557.

Iwakabe, S. (2011). Extending systematic case study method: generating and testing hypotheses about therapeutic factors through comparisons of successful and unsuccessful cases. Pragmatic Case Studies in Psychotherapy, 7(2): 339-350.

Iwakabe, S. and Gazzola, N. (2009). From single-case studies to practice-based knowledge: aggregating and synthesizing case studies. Psychotherapy Research, 19: 601-11.

Jacobson, N \& Truax, P (1991) Clinical Significance: A Statistical Approach to Defining Meaningful Change in Psychotherapy Research Journal of Consulting and Clinical Psychology Vol 59. No 1,12-19

Kerr, C. (2013) TA Treatment of Emetophobia - A Hermeneutic Single-Case Efficacy Design Study - 'Peter' International Journal of Transactional Analysis Research, 4: 2 15-26

Llewelyn, S. (1988). Psychological therapy as viewed by clients and therapists. British Journal of Clinical Psychology, 27: 22338.

Mackrill, T. (2008). Exploring psychotherapy clients' independent strategies for change while in therapy. British Journal of Guidance and Counselling, 36(4): 441-453.

McLeod, J. (2013). Process and outcome in pluralistic transactional analysis counselling for long-term health conditions: a case series. Counselling and Psychotherapy Research, 13(1): 32-43.

Slife, B.D., and Gantt, E.E. (1999). Methodological pluralism: a framework for psychotherapy research. Journal of Clinical Psychology, 55(12): 1453-1465.

van Rijn, B., Wild, C. and Moran, P. (2011). Evaluating the outcomes of transactional analysis psychotherapy and integrative counselling psychology within UK primary care settings. International Journal of Transactional Analysis Research, 2: 2:34-43.

Widdowson, M. (2012a). TA treatment of depression: a hermeneutic single-case efficacy design study- 'Peter'. International Journal of Transactional Analysis Research, 3(1): 3-13. 
Widdowson, M. (2012b). TA treatment of depression: a hermeneutic single-case efficacy design study- case two: "Denise". International Journal of Transactional Analysis Research, 3(2): 3-14.
Widdowson, M. (2012c). TA treatment of depression: a hermeneutic single-case efficacy design study- case three: "Tom". International Journal of Transactional Analysis Research, 3(2): 15-27. 